Research Article

\title{
Measurement and Analysis of Hydrogen Distribution in Stress Environment Using Vickers Microhardness Technique
}

\author{
Lei Gu $\mathbb{D},{ }^{1}$ Jing Wang $\mathbb{D},{ }^{1}$ Xiaoyang $L i \mathbb{D},{ }^{1}$ and Yanjun Zeng $\mathbb{D}^{2}$ \\ ${ }^{1}$ Department of Mechanical Engineering and Applied Electronics Technology, Beijing University of Technology, \\ Beijing 100124, China \\ ${ }^{2}$ Biomechanics and Medical Information Institute, Beijing University of Technology, Beijing 100022, China
}

Correspondence should be addressed to Yanjun Zeng; yjzeng@bjut.edu.cn

Received 3 May 2018; Revised 15 July 2018; Accepted 9 August 2018; Published 27 September 2018

Academic Editor: Fulvio Lavecchia

Copyright (C) 2018 Lei Gu et al. This is an open access article distributed under the Creative Commons Attribution License, which permits unrestricted use, distribution, and reproduction in any medium, provided the original work is properly cited.

\begin{abstract}
In this paper, the stress distribution field in front of the crack tip was obtained by loading a modified WOL specimen using a bolt. Considering the relationship between microhardness and hydrogen content or internal stress in the metal, a model based on the change of microhardness increment is proposed to describe the trend of hydrogen concentration distribution in the stress environment. The agreement between theoretical model and experimental results is verified by the Vickers microhardness tester. Based on the model, there is a simple additive relationship between the hydrogen-induced microhardness increment and the stress-induced microhardness increment. Therefore, the microhardness tester can be employed to evaluate the hydrogen distribution in metals quantitatively. The experimental results demonstrated that the Vickers microhardness method has accurately revealed the hydrogen concentration behavior accurately in a known equibiaxial stress environment. The hydrogen distribution of specimens in the stress environment was analyzed by taking the change of the microhardness increment along the crack propagation direction of specimens as the indicator.
\end{abstract}

\section{Introduction}

Hydrogen is regarded as a clean and green resource of energy. Hydrogen energy technology has attracted extensive attention with the industrialization of hydrogen fuel cells and hydrogen energy automobile. More and more production equipment is exposed to a hydrogen-containing environment. As a result of the working stress and external stress, the equipment is usually in a low-cycle fatigue working condition in the engineering environment. The stress and hydrogen in the metal can degrade its mechanical properties overtime. Therefore, in order to determine the mechanism for hydrogen corrosion in the stress environment and to ensure the safety of equipments exposed to hydrogen, the hydrogen distribution behavior in the stress environment has to be understood $[1,2]$. However, it is very difficult in experimental evaluation of the hydrogen concentration behavior in the project site.

The determination of hydrogen distribution in metals has always been the focus and difficulty in the study of hydrogen corrosion. Currently, the proved effective methods include SIMS [3-5], isotope tracer [6], gaseous hydrogen permeation, electrochemical hydrogen permeation $[7,8]$, hydrogen desorption isotherms, Gorsky effect, and microhardness distribution method.

In the experimental evaluation of the hydrogen concentration behavior in the stress environment, it has been reported in previous publications that $\mathrm{Yu}$ et al. [9] and Mao and $\mathrm{Li}[10]$ measured the hydrogen accumulation near the notch tip of hydrogen-charged modified wedge-openingloading (WOL) specimen under different $K_{\mathrm{I}}$ levels below $K_{\mathrm{C}}$ using the ion microprobe mass analyzer and obtained that the interaction between the stress and hydrogen at the crack tip influenced hydrogen distribution. Nagao et al. studied the effects of stress fields and hydrogen trapping on hydrogen transport in high-strength steels using hydrogen microprint technique and promoted the hydrogen transport by an applied stress field [11]. Takakuwa et al. have proved that X-ray diffraction can be used to measure the hydrogen concentration in stress environments due to the strong 
linear correlation between hydrogen content and hydrogen-induced strain. X-ray diffraction results show that hydrogen concentrated at the elastic-plastic boundary where the hydrostatic stress is a maximum, in accordance with the stress potential term [12]. Furthermore, Takakuwa et al. had posted that the hydrogen solubility became much higher due to the high strain and high dislocation density [12]. Chen et al. investigated the hydrogen transportation and distribution around the fatigue crack tip in type 304 stainless steel in the stress environment by using hydrogen microprint technique and thermal desorption spectrometry. The results show that hydrogen accumulated in the vicinity of the crack tip during the crack growth in the hydrogen gas environment [13].

However, the above experimental methods are all laboratory methods that are difficult to apply in engineering for some reasons, including the experimental device structure is complicated, the procedure is cumbersome, and the experimental expenses are high. The present study attempts to find a method suitable for the engineering environment to evaluate the hydrogen behavior of metals under stress precisely.

It has been reported in previous publications that the microhardness method can be one of the most important methods to evaluate the equibiaxial stress field [14-18]. Hardness is reduced by the tensile stress and increased by the compressive stress [19-22]. The microhardness distribution method is also an important method for measuring the distribution of hydrogen in metals. Many scholars have proved that the Vickers hardness increases as the hydrogen content increases in metals [23-28]. Furthermore, quite a few scholars have proved that the determination of hydrogen diffusivities in metals by subscale microhardness profiling is a versatile technique that can be used to obtain hydrogen diffusivities with simple experimentation; that is, the increase in hydrogen concentration is proportional to the increase in hardness [29-34]. Based on this, there is a possibility that the hydrogen concentration behavior in the stress environment can be evaluated through variation of the hardness detected by a microhardness tester.

Hydrogen concentration behavior in the stress environment is investigated by the microhardness tester in this paper. The stress environment is created by loading the modified wedge-opening-loading (WOL) specimen with a bolt. The stress state along the crack propagation direction of the specimen is an equibiaxial stress field with a theoretical solution. The corrosion environment is a saturated hydrogen sulfide solution. The measured microhardness increments in front of the crack before and after corrosion were compared.

\section{Theoretical Model}

2.1. Relationship between Stress and Microhardness. The following equation reveals that a substrate with a tensile stress develops a larger apparent contact area than the virgin material, when indented to the same load [14]:

$$
\frac{A_{\sigma}}{A_{\mathrm{b}}}=\left(1-\frac{\sigma_{\mathrm{h}}}{p_{\mathrm{ave}}}\right)^{-1}=\left(1-\frac{\sigma_{y, 0}}{p_{\mathrm{ave}}}\right)^{-1},
$$

where $A_{\sigma}$ is the apparent contact area for the substrate with a tensile stress, $A_{\mathrm{b}}$ is the apparent contact area for the virgin material without any stress, $\sigma_{\mathrm{h}}$ is the apparent tensile hydrostatic stress, which is equivalent to the equibiaxial tensile stress at the indented surface, $\sigma_{\mathrm{h}}=\sigma_{x, 0}=\sigma_{y, 0}$, and $p_{\text {ave }}$ refers to the average contact pressure, $p_{\mathrm{ave}}=P / A_{\mathrm{b}}, P$ is the experimental load.

In the process of indentation experiment, $\mathrm{HV}=P /\left(g_{\mathrm{n}} \cdot A\right)$, that is, with the same load, the hardness ratio of any two indentation points is inversely proportional to the ratio of the indentation area. Therefore, the hardness ratio is also a measure of the apparent area ratio, i.e., the ratio of the apparent area of contact for the substrate with a stress to that for the virgin substrate at a fixed indentation load:

$$
\begin{aligned}
\frac{\mathrm{HV}_{\mathrm{b}}}{\mathrm{HV}_{\sigma}} & =\frac{A_{\sigma}}{A_{\mathrm{b}}}=\left\{1-\frac{\sigma_{y, 0}}{p_{\text {ave }}}\right\}^{-1}=\left\{1-\frac{\sigma_{y, 0}}{P} \cdot A_{\mathrm{b}}\right\}^{-1} \\
& =\left\{1-\frac{\sigma_{y, 0}}{g_{\mathrm{n}} \cdot \mathrm{HV}_{\mathrm{b}}}\right\}^{-1} .
\end{aligned}
$$

The stress field then can simply be written as

$$
\begin{aligned}
\sigma_{y, 0} & =\left(\frac{\mathrm{HV}_{\sigma}}{\mathrm{HV}_{\mathrm{b}}}-1\right) \cdot \frac{P}{A_{\mathrm{b}}}=\left(\frac{\mathrm{HV}_{\sigma}}{\mathrm{HV}_{\mathrm{b}}}-1\right) \cdot g_{\mathrm{n}} \cdot \mathrm{HV}_{\mathrm{b}} \\
& =\Delta \mathrm{HV}_{\sigma} \cdot g_{\mathrm{n}}, \\
\Delta \mathrm{HV}_{\sigma} & =\sigma_{y, 0} / g_{\mathrm{n}},
\end{aligned}
$$

where $g_{\mathrm{n}}$ is the normal acceleration of gravity, $g_{\mathrm{n}}=9.8 \mathrm{~m} / \mathrm{s}^{2}$, $\mathrm{HV}_{\mathrm{b}}$ is the original hardness of stress-free area, $\mathrm{HV}_{\sigma}$ is the micro-hardness of stress area at any point, and $\Delta \mathrm{HV}_{\sigma}$ is the micro-hardness increment of stress area at any point.

\subsection{Theoretical Model of Hydrogen Concentration Distribu-} tion in the Stress Environment. In this study, the diffused hydrogen atoms tend to accumulate around the high-stress field, interfaces, and grain boundaries, leading to the main hydrogen damage that can be obtained by means of stressinduced diffusion, which is given by Dean [35]:

$$
c_{\sigma}=c_{0} \exp \left(\frac{\overline{V_{\mathrm{H}}} \cdot \sigma_{\mathrm{h}}}{R \cdot T}\right)
$$

where $c_{\sigma}$ is the hydrogen concentration when $\sigma_{\mathrm{h}}=\sigma, c_{0}$ is the hydrogen concentration when $\sigma_{\mathrm{h}}=0, \overline{V_{\mathrm{H}}}$ is the partial molar volume of hydrogen, $\sigma_{\mathrm{h}}$ is the hydrostatic stress, $R$ is the gas constant, and $T$ is the thermodynamic temperature of the test environment.

Since the increase in hydrogen concentration is proportional to the increase in hardness, the relative hydrogen concentration of $\sigma_{\mathrm{h}}=\sigma$ is

$$
\Delta \mathrm{HV}_{\mathrm{c}_{\sigma}}=\frac{c_{\sigma}}{c_{0}} \cdot \Delta \mathrm{HV}_{\mathrm{c}_{0}}=\Delta \mathrm{HV}_{\mathrm{c}_{0}} \exp \left(\frac{\overline{V_{\mathrm{H}}} \cdot \sigma_{\mathrm{h}}}{R \cdot T}\right),
$$


where $\Delta \mathrm{HV}_{\mathrm{c}_{\sigma}}$ is the hydrogen-induced microhardness increment when $\sigma_{\mathrm{h}}=\sigma$ and $\Delta \mathrm{HV}_{\mathrm{c}_{0}}$ is the hydrogen-induced microhardness increment when $\sigma_{\mathrm{h}}=0$.

For a modified WOL specimen, the plane strain fields $\sigma_{\mathrm{e}}$ along the crack propagation direction in front of the crack tip can be obtained by the following equation:

$$
\sigma_{\mathrm{e}}= \begin{cases}\sigma_{\mathrm{s}}, & r \leq r_{0}, \\ \frac{K_{\mathrm{I}}}{Y \cdot \sqrt{2 r}}, & r>r_{0},\end{cases}
$$

where $\sigma_{\mathrm{s}}$ is the yield stress of the metal and $K_{\mathrm{I}}$ is the stress intensity factor, and the relationship between stress intensity factor $K_{\mathrm{I}}$ and the crack length $a$ for the WOL specimen can be calculated by

$$
K_{\mathrm{I}}=\frac{Y \cdot P}{B \cdot \sqrt{a}}
$$

where $Y$ is the stress intensity factor coefficient, which is derived from stress analysis for a sample of a particular geometric shape, $P$ is the loading force, and $B$ is the thickness of the specimen.

In Equation (7), $r$ is the distance from the crack tip to the measurement point, and $r_{0}$ is the boundary of the plastic region in the front of crack tip. For a fixed $K_{\mathrm{I}}$,

$$
r_{0}=\frac{1}{2}\left(\frac{Y \cdot \sigma_{s}}{K_{I}}\right)^{2}
$$

In a stress-induced hydrogen corrosion environment, it is assumed that the microhardness increment along the crack propagation direction of the specimen can be generally divided into two parts: plane strain theoretical stressinduced microhardness increment and the hydrogeninduced microhardness increment. The relationship can be given by the following equation:

$$
\Delta \mathrm{HV}=\Delta \mathrm{HV}_{\sigma}+\Delta \mathrm{HV}_{\mathrm{c}_{\sigma}}=\sigma_{y, 0} / g_{\mathrm{n}}+\Delta \mathrm{HV}_{\mathrm{c}_{\sigma}} \cdot \exp \left(\frac{\overline{V_{\mathrm{H}}} \cdot \sigma_{\mathrm{h}}}{R \cdot T}\right)
$$

\section{Experimental Procedures}

A modified WOL specimen of \#45 steel was employed in this research, as shown in Figure 1. The chemical compositions (mass \%) of the tested steel are shown in Table 1. The measured yield stress of the steel was $345 \mathrm{MPa}$.

The stress intensity factor $K_{\mathrm{I}}$ of the crack tip was determined by the opening displacement of the crack using a bolt, $K_{\mathrm{I}}=45 \mathrm{MPa} \cdot \mathrm{m}^{0.5}$. The specimens were soaked in saturated hydrogen sulfide solution (2300 ppm) and divided into 3 groups according to different corrosion periods $(24 \mathrm{~h}$, $48 \mathrm{~h}$, and $72 \mathrm{~h}$ ). Each group has 3 specimens to verify the reproducibility of the test.

The Zwick Roell Zhu 2.5 hardness tester produced in Germany was used to measure the hardness distribution in front of the crack before and after corrosion. Vickers hardness HV0.2 was chosen as the hardness index of the

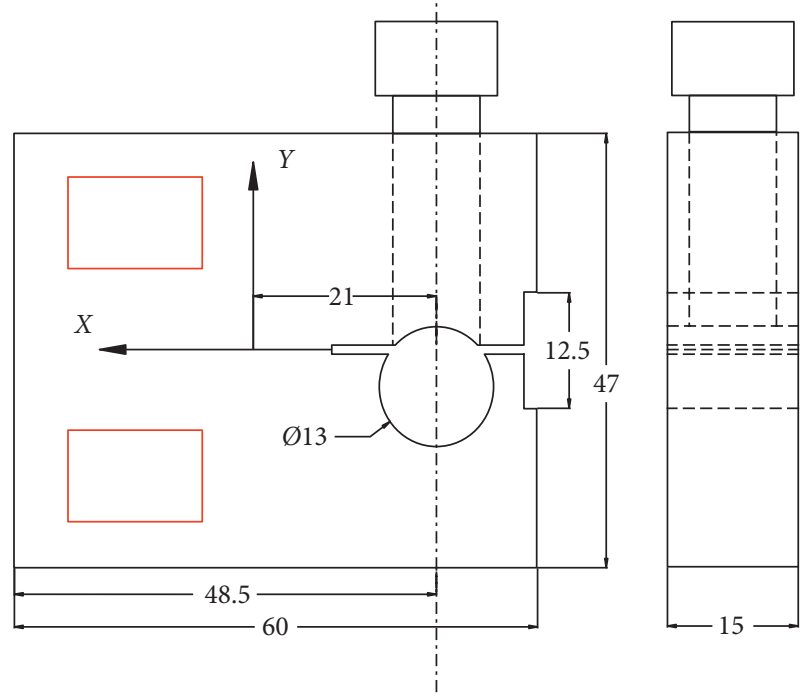

Figure 1: The modified WOL specimen (reproduced from Gu et al. [36], under the Creative Commons Attribution License/public domain).

TAble 1: Chemical composition of the tested steel (mass \%) (reproduced from Gu et al. [36], under the Creative Commons Attribution License/public domain).

\begin{tabular}{lcccccc}
\hline $\mathrm{C}$ & $\mathrm{Si}$ & $\mathrm{Mn}$ & $\mathrm{S}$ & $P$ & $\mathrm{Cr}$ & $\mathrm{Ni}$ \\
\hline 0.46 & 0.27 & 0.65 & 0.015 & 0.018 & 0.20 & 0.214 \\
\hline
\end{tabular}

material. Starting from the crack tip, the microhardness values were obtained at the intervals of $80-100 \mu \mathrm{m}$ progressing along the crack propagation direction of the specimen. Hardness was measured until it reached a constant value. For comparison purposes, 10 random hardness points of the specimen surface far from the crack tip were measured to determine the hardness value of stress-free area (Figure 1, the area enclosed by the red box). The hardness of the two surfaces of each specimen is measured.

\section{Results}

4.1. Microhardness Increment of Stress-Free Area after Corrosion. The mean and standard deviation of the microhardness increment values of stress-free area with different corrosion periods are shown in Figure 2. Subtracting the measured hardness value before corrosion from the measured hardness value after corrosion, the microhardness increment value under different corrosion periods can be obtained. The change in the hardness value of stressfree area after corrosion is the result of individual effect of hydrogen corrosion. Student's $t$-test for quantitative variables and chi-squared test for qualitative variables were used for statistical analysis. It can be seen from the results that there is no significant difference $(P>0.05)$ in microhardness increment with different corrosion periods.

4.2. Microhardness Increment along the Crack Propagation Direction of Specimens before and after Corrosion. 


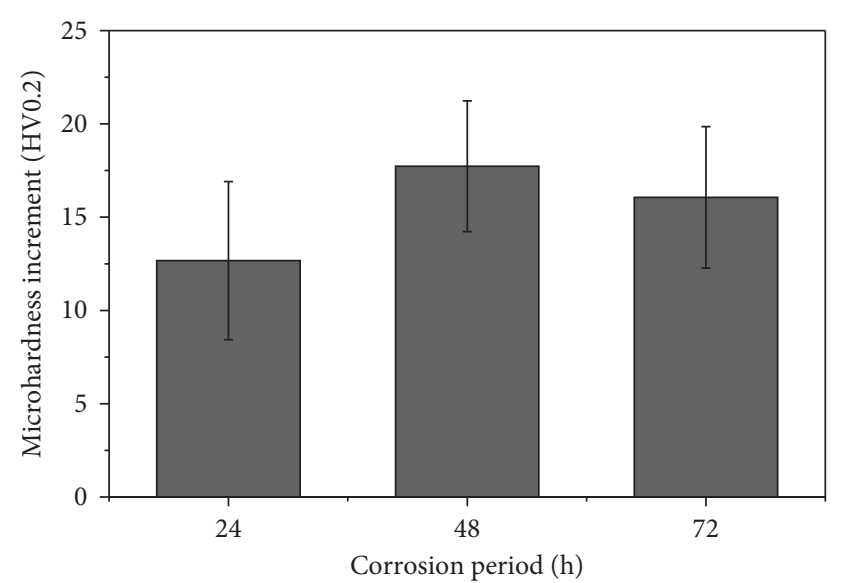

Figure 2: Microhardness increment for each group. The $P$ value is the probability of obtaining a result at least as extreme as the one that was actually observed, given that the null hypothesis is true. When $P>0.05$, there is no significant difference in microhardness increment with different periods.

The microhardness increment distribution was calculated along the crack propagation direction of multiple groups of specimens after soaking for $0 \mathrm{~h}, 24 \mathrm{~h}, 48 \mathrm{~h}$, and $72 \mathrm{~h}$ in saturated hydrogen sulfide solution, respectively, as shown in Figure 3. The vertical axis represents the microhardness value of the material, and the horizontal axis represents the distance from the crack tip. The microhardness increment is obtained by calculating the difference between the measured hardness and the hardness under stress-free and no corrosion conditions.

In Figure 3, the black square line represents the microhardness increment distribution curve along the crack propagation direction of each specimen under the no corrosion condition. The red circular line represents the microhardness increment distribution curve along the crack propagation direction of each specimen after soaking for 24 hours in saturated hydrogen sulfide solution. The blue triangular line represents the microhardness increment distribution curve along the crack propagation direction of each specimen after soaking in saturated hydrogen sulfide solution for 48 hours. The green triangle line represents the microhardness increment distribution curve along the crack propagation direction of each specimen after soaking in saturated hydrogen sulfide solution for 72 hours.

\section{Discussion}

5.1. Relationship between Applied Stress and Microhardness Increment. The blue line in Figure 4 shows that the average measured microhardness increment distribution curve along the crack propagation direction, which is calculated by averaging the microhardness increment distributions of the no corrosion condition. In Figure 4, the blue vertical axis represents the microhardness value of the material, the black horizontal axis represents the distance from the crack tip, the blue horizontal solid line is the average hardness values, the horizontal dotted line is the standard deviations of the hardness value, the blue vertical solid line is the mean distance from the crack tip, and the vertical dotted line is the standard deviation of the distance from the crack tip.

The red line in Figure 4 shows that the theoretical stress $\left(\sigma_{y}=\sigma_{\mathrm{e}}\right)$ distribution curve along the crack propagation direction of specimens. The red vertical axis represents the stress value, and the black horizontal axis represents the distance from the crack tip.

In Figure 4, the microhardness increment distribution is consistent with the applied stress distribution. The result shows that the stress-induced microhardness increment is due to the presence of stress. To reveal the influence of the applied stress $\Delta \sigma$ on the microhardness, the relationship between the applied stress $\Delta \sigma$ and the stress-induced microhardness increment $\Delta \mathrm{HV}_{\sigma}$ was investigated, as shown in Figure 5.

From Figure 5, in the no corrosion environment, the microhardness increment versus the applied stress fields have strong linear correlation with a correlation coefficient, $R$, of 0.98 and significance level of $0.04 \cdot 10^{-14}$. Therefore, an equation describing the relationship between the applied stress and the microhardness increment can be given as follows:

$$
\Delta \sigma=k_{\mathrm{const}} \cdot \Delta \mathrm{HV}_{\sigma},
$$

where $\Delta \sigma=\sigma-\sigma_{\mathrm{b}}, \Delta \mathrm{HV}_{\sigma}=\mathrm{HV}_{\sigma}-\mathrm{HV}_{\mathrm{b}}, \sigma$ is the stress at any point along the direction of crack propagation, $\sigma_{\mathrm{b}}$ is the corrected stress value of the applied stress, HV is the Vickers hardness at any point along the direction of the crack propagation, $\mathrm{HV}_{\mathrm{b}}$ is the Vickers hardness of stress-free area, and $k_{\text {const }}$ is a constant of proportionality, equal to -10 in the present study.

This is in accord with the result of stress estimation by Suresh and Giannakopoulos [14] using the indentation theory, as is shown in Equation (4).

Therefore, in the no corrosion environment, the stress can be described using the stress-induced microhardness increment linearly as follows:

$$
\sigma-144=\Delta \mathrm{HV}_{\sigma} \cdot(-10)
$$

Equation (12) reveals that the stress distribution in front of the crack tip can be evaluated precisely using the microhardness method. For a modified WOL specimen with a fixed stress factor $K_{\mathrm{I}}$,

$$
\Delta \mathrm{HV}_{\sigma}= \begin{cases}\frac{-\left(\sigma_{\mathrm{s}}-144\right)}{10}, & r \leq r_{0}, \\ -\left(\frac{K_{\mathrm{I}}}{Y \sqrt{2 r}}-144\right) / 10, & r>r_{0} .\end{cases}
$$

5.2. The Hydrogen Distribution in the Stress Environment. The blue line in Figure 6 shows that the experimental average microhardness increment distribution (experimental microhardness increment) along the crack propagation direction of all specimens under the combined effect of applied stress and hydrogen corrosion, which is calculated 


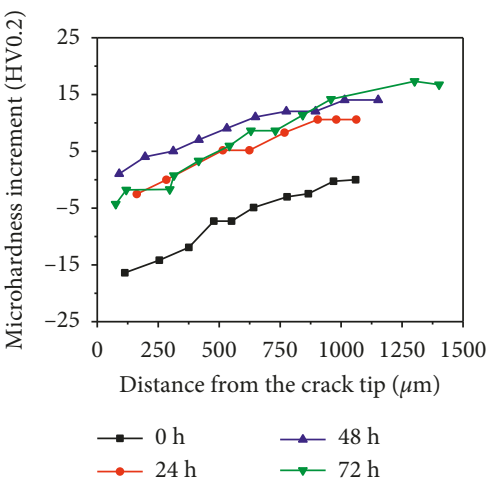

(a)

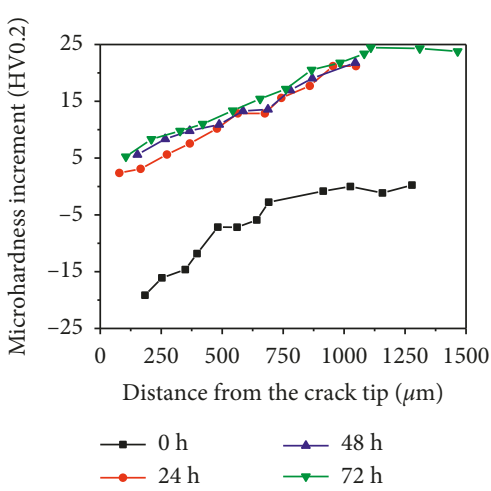

(d)

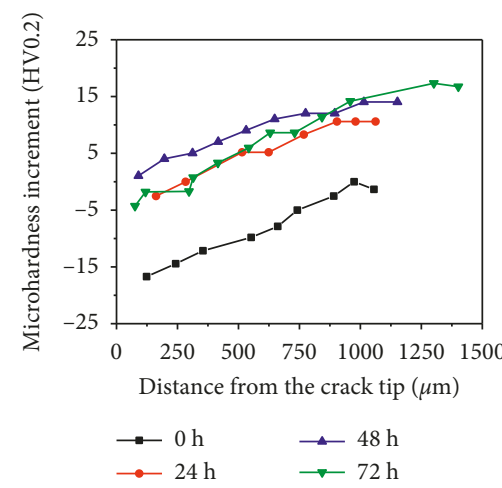

(b)

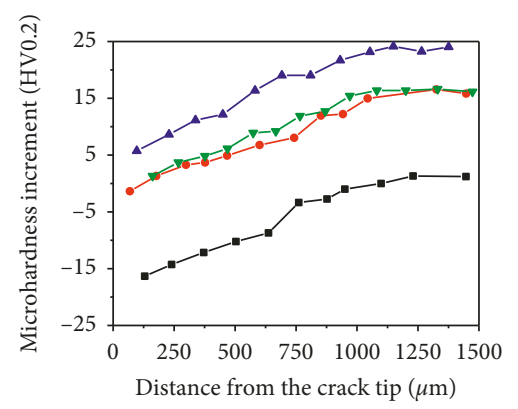

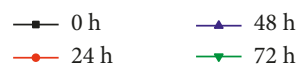

(e)

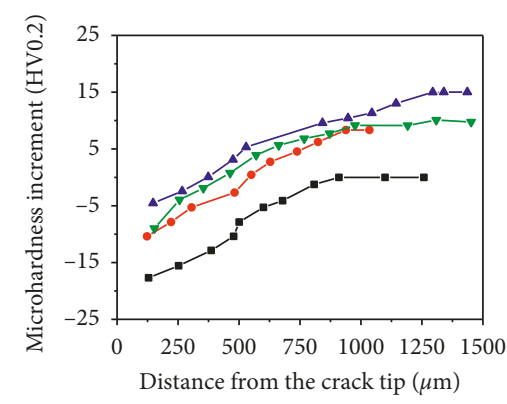

$$
\because 0 \mathrm{~h} \quad \longrightarrow 48 \mathrm{~h}
$$$$
\because 24 \mathrm{~h} \quad \rightarrow 72 \mathrm{~h}
$$

(c)

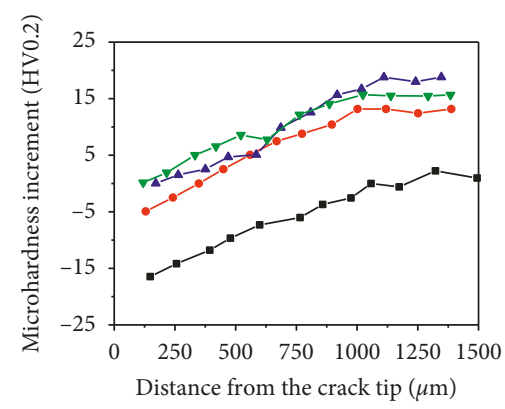

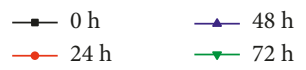

(f)

FIGURE 3: Microhardness increment distribution curves along the crack propagation direction of specimens before and after corrosion.

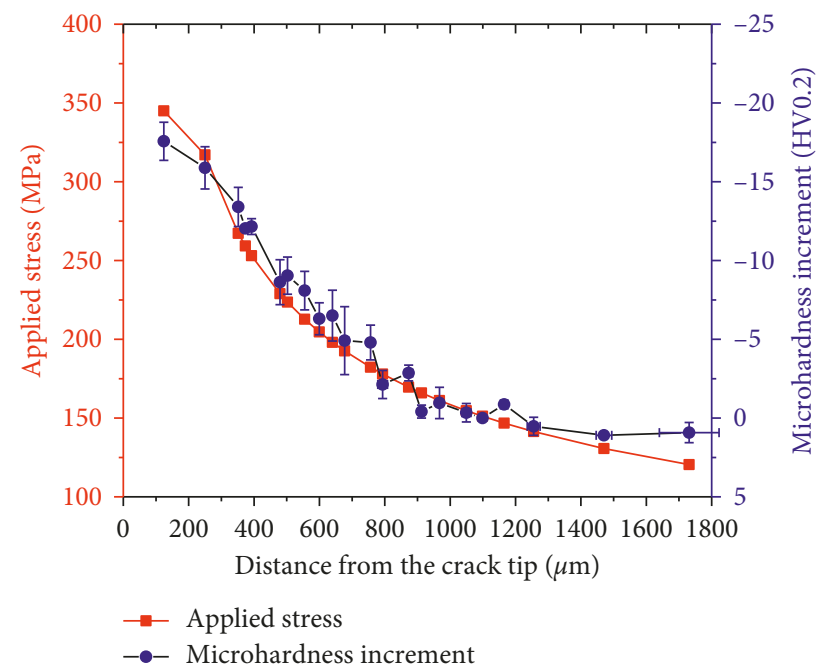

FIGURE 4: Calculated applied stress and microhardness increment distribution along the crack propagation direction of specimens. $K_{\mathrm{I}}=45 \mathrm{MPa} \cdot \mathrm{m}^{0.5}$, the distribution is the average of all specimens.

by averaging the microhardness increment distributions of the same corrosion period in Figure 3. In Figure 3, the curves under the same corrosion period have a strong consistency, indicating the stability of the corrosion soaking in saturated hydrogen sulfide solution.

The red line in Figure 6 shows the plane strain theoretical stress-induced microhardness increment distribution (stress-

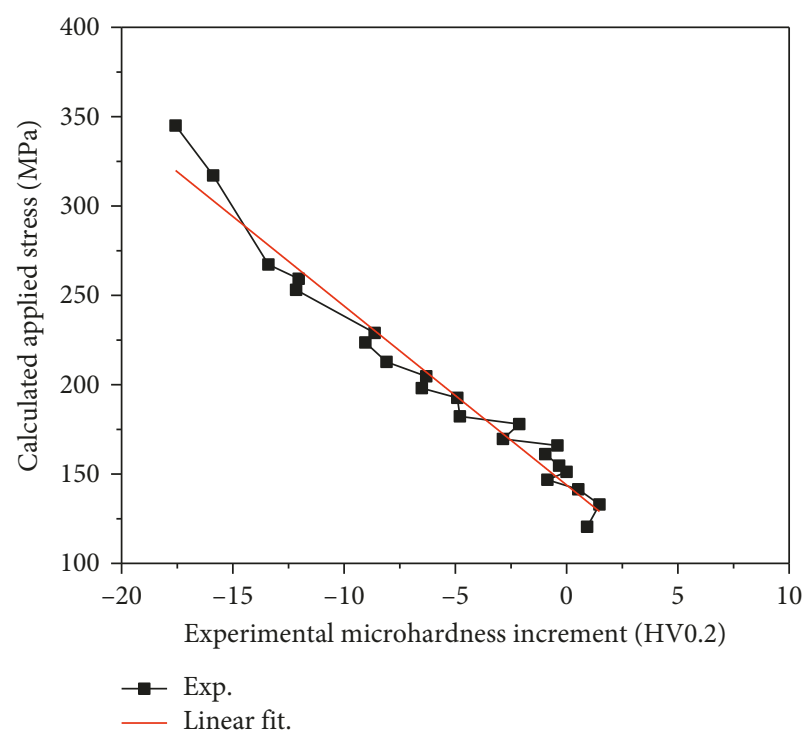

FIGURE 5: Linear relationship between applied stress and microhardness increment. $K_{\mathrm{I}}=45 \mathrm{MPa} \cdot \mathrm{m}^{0.5}$, the distribution is the average of all specimens. The relationship can be represented by Equation (11), which is calculated by a least squares approximation.

induced microhardness increment) along the crack propagation direction of specimens without hydrogen corrosion, which was obtained from the relationship between stress and microhardness increment (Equation (12)). 


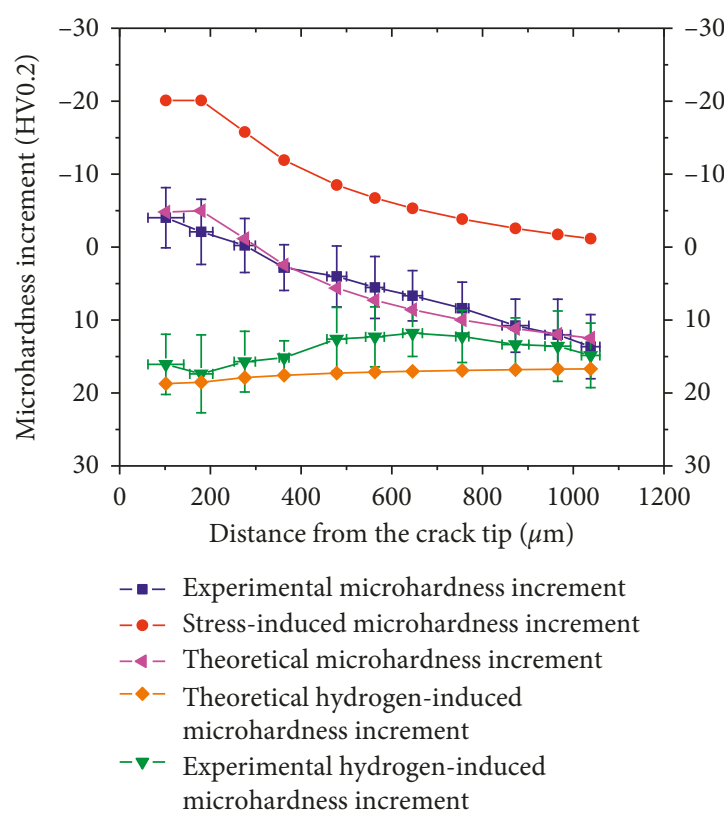

(a)

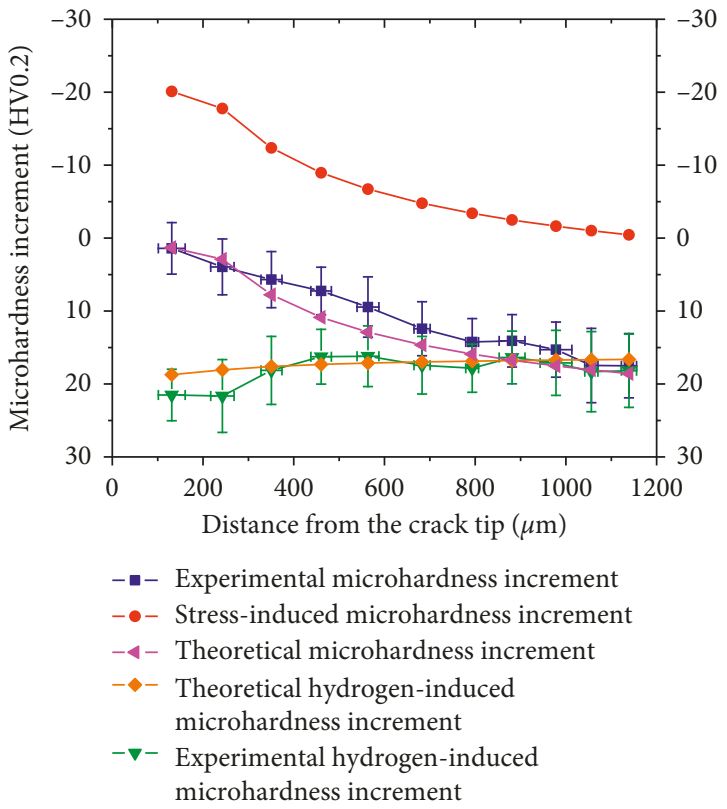

(b)

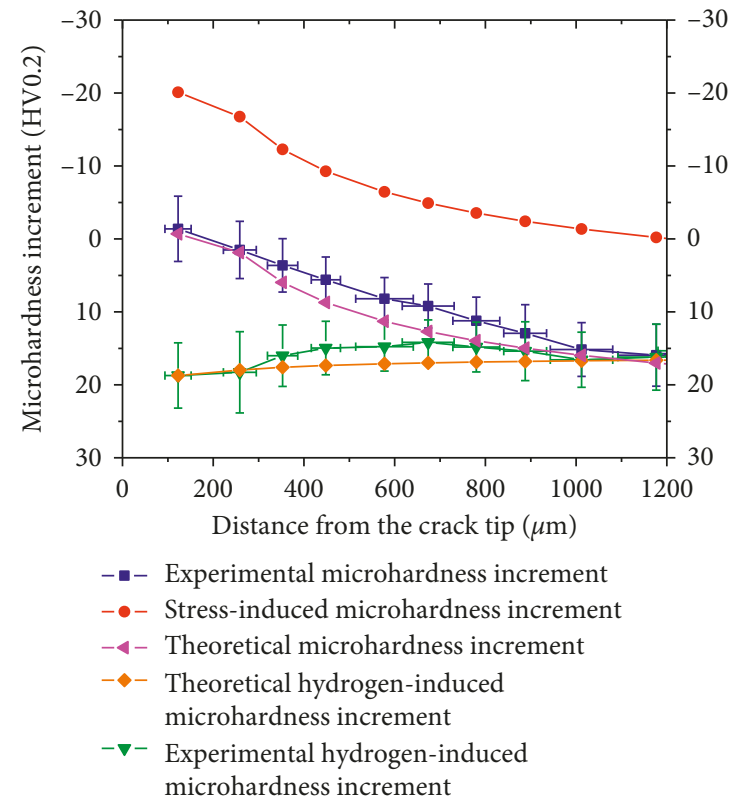

(c)

FIGURE 6: Theoretical and experimental contrast curves of microhardness increment-distance from the crack tip (a) with $24 \mathrm{~h}$ corrosion period, (b) with $48 \mathrm{~h}$ corrosion period, and (c) with $72 \mathrm{~h}$ corrosion period.

Subtracting the red line (micro-hardness increment distribution curve under the no corrosion condition) from the blue line (microhardness increment distribution curve under the corrosion condition), a new micro-hardness increment distribution curve is obtained, shown as the green line in Figure 6.

The orange line in Figure 6 shows that the hydrogeninduced microhardness increment (theoretical hydrogeninduced microhardness increment) along the crack propagation direction of the WOL specimen, which can be calculated by Equation (6). The hydrostatic stress under plane stress state is $\sigma_{\mathrm{e}}=\left(\sigma_{1}+\sigma_{2}+\sigma_{3}\right) / 3=2 \sigma_{\mathrm{e}} / 3$.

The obtained green line is the experimental curve of hydrogen-induced microhardness increment (experimental hydrogen-induced microhardness increment) distribution along the crack propagation direction of specimens because the green line and the orange line are in good agreement with each other. Therefore, the hydrogen distribution behavior in the stress environment can be successfully measured using the microhardness method. In the actual project, 
as long as the stress environment is a known equibiaxial stress environment, the microhardness method can be used to accurately obtain the hydrogen concentration distribution in the equipment.

This also reveals that, under the combined effect of applied stress and hydrogen corrosion, the measured microhardness increment can be generally divided into two parts: plane strain theoretical stress-induced microhardness increment and the hydrogen-induced microhardness increment. In this study, the relationship can be given by the following equation:

$$
\begin{aligned}
\Delta \mathrm{HV}=\Delta \mathrm{HV}_{\sigma}+\Delta \mathrm{HV}_{\mathrm{c}_{\sigma}} \\
= \begin{cases}\frac{-\left(\sigma_{\mathrm{s}}-144\right)}{10}+\Delta \mathrm{HV}_{\mathrm{c}_{0}} \exp \left(\frac{\overline{V_{\mathrm{H}}} \cdot \sigma_{\mathrm{h}}}{R \cdot T}\right), & r \leq r_{0}, \\
-\left(\frac{K_{\mathrm{I}}}{Y \sqrt{2 r}}-144\right) / 10+\Delta \mathrm{HV}_{\mathrm{c}_{0}} \exp \left(\frac{V_{\mathrm{H}} \cdot \sigma_{\mathrm{h}}}{R \cdot T}\right), & r \geq r_{0} .\end{cases}
\end{aligned}
$$

\section{Conclusions}

In this paper, the hydrogen distribution of specimens in the stress environment was analyzed by taking the change of the microhardness increment along the crack propagation direction of specimens as the indicator. The conclusions are summarized as follows:

(1) In the corrosive environment, the hardness along the crack propagation direction of the specimen is significantly affected by stress and hydrogen concentration. The Vickers microhardness method can accurately reveal the hydrogen concentration behavior accurately in a known equibiaxial stress environment. The microhardness method can be employed to accurately evaluate the hydrogen concentration distribution in the engineering parts.

(2) In the Vickers microhardness measurement, there is a simple additive relationship between stress-induced microhardness increment and hydrogen-induced microhardness increment. The experimental results showed that the distribution of hydrogen corrosion concentration in the stress environment along the crack propagation direction of the specimen was consistent with the theoretical relationship between hydrostatic stress and hydrogen corrosion concentration.

(3) The experimental results showed that the applied stresses have good linear correlation with microhardness increment in the no corrosion environment, and the scale factor was -10 . This showed that the closer the crack tip, the greater the stress and the smaller the microhardness.

\section{Data Availability}

The data used to support the findings of this study are available from the corresponding author upon request.

\section{Conflicts of Interest}

The authors declare that they have no conflicts of interest.

\section{Acknowledgments}

This article is supported by the National Key Research and Development Program of China (Project no. 2016YFC0801905-16).

\section{References}

[1] T. Cho, D. J. Delgado-Hernandez, K.-H. Lee, B.-J. Son, and T.-S. Kim, "Bayesian correlation prediction model between hydrogen-induced cracking in structural members," Metals, vol. 7, no. 6, pp. 205-222, 2017.

[2] P. A. S. Pereira, C. S. G. Franco, J. L. M. Guerra Filho, and D. S. dos Santos, "Hydrogen effects on the microstructure of a $2.25 \mathrm{Cr}-1 \mathrm{Mo}-0.25 \mathrm{~V}$ steel welded joint," International Journal of Hydrogen Energy, vol. 40, no. 47, pp. 17136-17143, 2015.

[3] J. Yamabe, S. Matsuoka, and Y. Murakami, "Surface coating with a high resistance to hydrogen entry under high-pressure hydrogen-gas environment," International Journal of $\mathrm{Hy}$ drogen Energy, vol. 38, no. 24, pp. 10141-10154, 2013.

[4] J. Yamabe, O. Takakuwa, H. Matsunaga, H. Itoga, and S. Matsuoka, "Hydrogen diffusivity and tensile-ductility loss of solution-treated austenitic stainless steels with external and internal hydrogen," International Journal of Hydrogen Energy, vol. 42, no. 18, pp. 13289-13299, 2017.

[5] O. Takakuwa, J. Yamabe, H. Matsunaga, Y. Furuya, and S. Matsuoka, "Comprehensive understanding of ductility loss mechanisms in various steels with external and internal hydrogen," Metallurgical and Materials Transactions A, vol. 48, no. 11, pp. 5717-5732, 2017.

[6] M. Tupin, F. Martin, C. Bisor et al., "Hydrogen diffusion process in the oxides formed on zirconium alloys during corrosion in pressurized water reactor conditions," Corrosion Science, vol. 116, pp. 1-13, 2017.

[7] M. A. V. Devanathan and Z. Stachurski, "The adsorption and diffusion of electrolytic hydrogen in palladium," Proceedings of the Royal Society of London, vol. 270, no. 1340, pp. 90-102, 1962.

[8] C. H. Tseng, W. Y. Wei, and J. K. Wu, "Electrochemical methods for studying hydrogen diffusivity, permeability, and solubility in AISI 420 and AISI 430 stainless steels," Materials Science and Technology, vol. 5, no. 12, pp. 1236-1239, 1989.

[9] G. H. Yu, Y. H. Cheng, L. Chen, L. J. Qiao, Y. B. Wang, and W. Y. Chu, "Hydrogen accumulation and hydrogen-induced cracking of API C90 tubular steel," Corrosion, vol. 53, no. 10, pp. 762-769, 1997.

[10] S. X. Mao and M. Li, "Mechanics and thermodynamics on the stress and hydrogen interaction in crack tip stress corrosion: experiment and theory," Journal of the Mechanics and Physics of Solids, vol. 46, no. 6, pp. 1125-1137, 1998.

[11] A. Nagao, S. Kuramoto, and K. Ichitani, "Visualization of hydrogen transport in high strength steels affected by stress fields and hydrogen trapping," Scripta Materialia, vol. 45, no. 10, pp. 1227-1232, 2001.

[12] O. Takakuwa, T. Fujisawa, and H. Soyama, "Experimental verification of the hydrogen concentration around a crack tip using spot X-ray diffraction," International Journal of Hydrogen Energy, vol. 41, no. 48, pp. 23188-23195, 2016. 
[13] X. Chen, C. Zhou, X. Cai, J. Zheng, and L. Zhang, "Effects of external hydrogen on hydrogen transportation and distribution around the fatigue crack tip in type 304 stainless steel," Journal of Materials Engineering and Performance, vol. 26, no. 10, pp. 4990-4996, 2017.

[14] S. Suresh and A. E. Giannakopoulos, "A new method for estimating residual stress by instrumented sharp indentation," Acta Materialia, vol. 46, no. 16, pp. 5755-5767, 1998.

[15] S. Carlsson and P. L. Larsson, "On the determination of residual stress and strain fields by sharp indentation testing part I: Theoretical and numerical analysis," Acta Materialia, vol. 49, no. 12, pp. 2179-2191, 2001.

[16] S. Carlsson and P. L. Larsson, "On the determination of residual stress and strain fields by sharp indentation testing part II: Experiment investigation," Acta Materialia, vol. 49, no. 12, pp. 2193-2203, 2001.

[17] G. Bolzon and V. Buljak, "An indentation-based technique to determine in-depth residual stress profiles induced by surface treatment of metal components," Fatigue \& Fracture of Engineering Materials \& Structures, vol. 34, no. 2, pp. 97-107, 2011.

[18] J. Liu, D. Ye, L. Zhang, and L. Xiao, "Depth-sensing indentation measurement and finite element analysis of residual stress field near fatigue crack tip," Acta Aeronautica ET Astronautica Sinica, vol. 33, no. 12, pp. 2211-2220, 2012.

[19] S. Kokubo, On the Change in Hardness of a Plate Caused by Bending, vol. 1, pp. 256-267, Scientific Reports Tohoku Imperial University, Tohoku Imperial University, Sendai, Japan, 1932.

[20] G. Sines and R. Carlson, "Hardness measurements for determination of residual stress," ASTM Bulletin, vol. 180, pp. 35-37, 1952.

[21] J. Frankel, W. Scholz, and G. Capsimalis, "Residual stress measurement in circular steel cylinders," Ultrasonics Symposium, vol. 2, pp. 1009-1012, 1983.

[22] E. Frutos, M. Multigner, and J. L. Gonzalez-Carrasco, "Novel approaches to determining residual stresses by ultramicroindentation techniques: application to sandblasted austenitic stainless steel," Acta Materialia, vol. 58, no. 12, pp. 4191-4198, 2010.

[23] Y. Murakami, T. Kanezaki, and Y. Mine, "Hydrogen Effect against Hydrogen Embrittlement," Metallurgical and Materials Transactions A, vol. 41, no. 10, pp. 2548-2562, 2010.

[24] M. Śmiałowski, "Effects of hydrogen on the mechanical properties of steel," Hydrogen in Steel, pp. 211-213, Pergamon Press, Oxford, UK, 1962.

[25] K. A. Nibur, D. F. Bahr, and B. P. Somerday, "Hydrogen effects on dislocation activity in austenitic stainless steel," Acta Materialia, vol. 54, no. 10, pp. 2677-2684, 2006.

[26] A. S. El-Amoush, "An investigation of hydrogen-induced hardening in 7075-T6 aluminum alloy," Journal of Alloys and Compounds, vol. 465, no. 1-2, pp. 497-501, 2008.

[27] B. Swieczko-Zurek, A. Zielinski, and E. Lunarska, "Hydrogen degradation of structural steels in technical hydrocarbon liquids," Materials and Corrosion, vol. 59, no. 4, pp. 289-295, 2008.

[28] K. Stepien and M. Kupka, "Effect of hydrogen on roomtemperature hardness of $\mathrm{B} 2 \mathrm{FeAl}$ alloys," Scripta Materialia, vol. 59, no. 9, pp. 999-1001, 2008.

[29] P. Kumar and R. Balasubramaniam, "Determination of hydrogen diffusivity in austenitic stainless steels by subscale microhardness profiling," Journal of Alloys and Compounds, vol. 255, no. 1-2, pp. 130-134, 1997.
[30] H. Hosoda, K. Yoshimi, K. Inoue, and S. Hanada, "Effect of wet environment on hardness and yield stress of B2 Fe-Al alloys," Materials Science and Engineering A, vol. 258, no. 1-2, pp. 135-145, 1998.

[31] N. Ansari and R. Balasubramaniam, "Determination of hydrogen diffusivity in nickel by subsurface micro-hardness profiling," Materials Science and Engineering, vol. 293, no. 1-2, pp. 292-295, 2000.

[32] Z. Li, T. Chen, and Z. Zeng, "Hydrogen and its diffusion coefficient in stainless steels during electrochemically induced annealing," Journal of Beijing University of Chemical Technology, vol. 32, no. 5, pp. 60-63, 2005.

[33] J. Zhao, H. Ding, and W. Zhao, "Influence of thermohydrogen treatment on microstructural evolution and hardness of Ti600 alloy," Chinese Journal of Materials Research, vol. 22, no. 3, pp. 262-268, 2008.

[34] H. Xiao, J. Zhao, and W. Zhao, "Influence of hydrogenation on microstructure and hardness of Ti6Al4V alloy," Rare Metal Materials and Engineering, vol. 37, no. 10, pp. 1795-1799, 2008.

[35] S. W. Dean Jr., Review of Recent Studies on the Mechanism of Stress-Corrosion Cracking in Austenitic Stainless Steels, ASTM STP 610. Stress Corrosion-New approaches, pp.308-337, ASTM International, Philadelphia, PA, USA, 1976.

[36] L. Gu and X. Li, "Hydrogen damage in metals. 7th International Conference on Nanomaterials and Materials Engineering," IOP Conference Series: Materials Science and Engineering, vol. 380, no. 1, article 012016, 2018. 


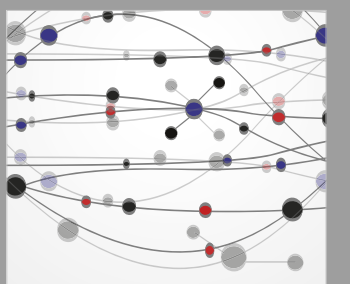

The Scientific World Journal
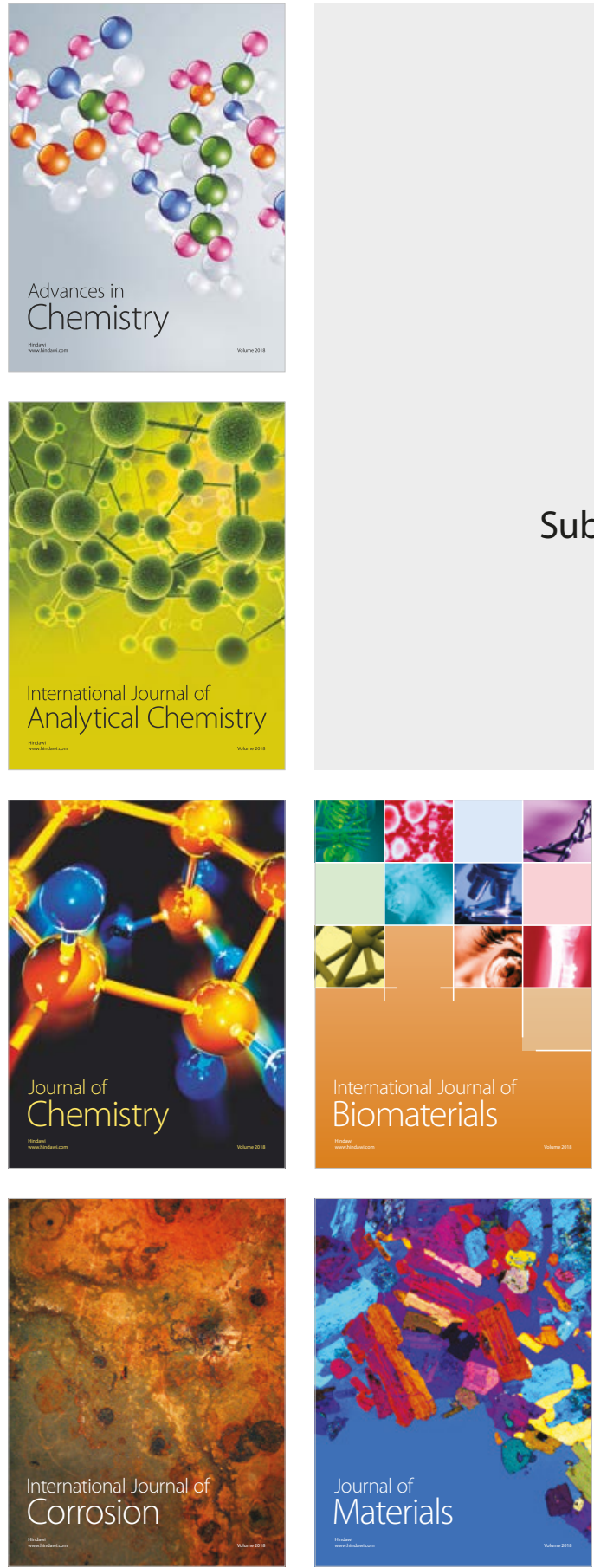

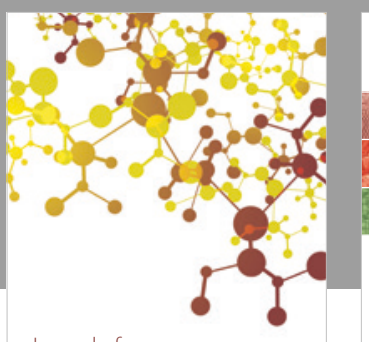

Journal of

Applied Chemistry
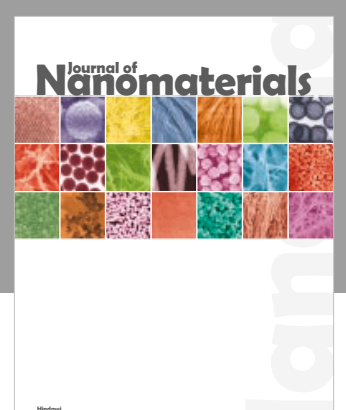

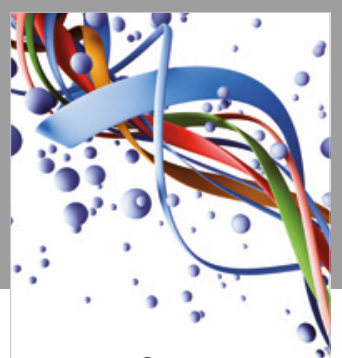

Scientifica

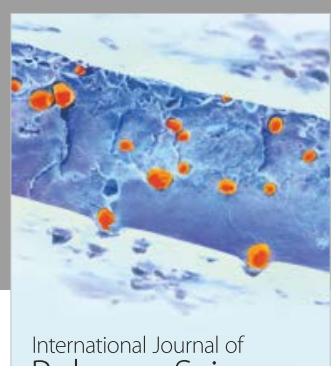

Polymer Science

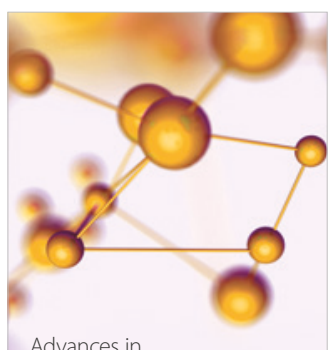

Physical Chemistry
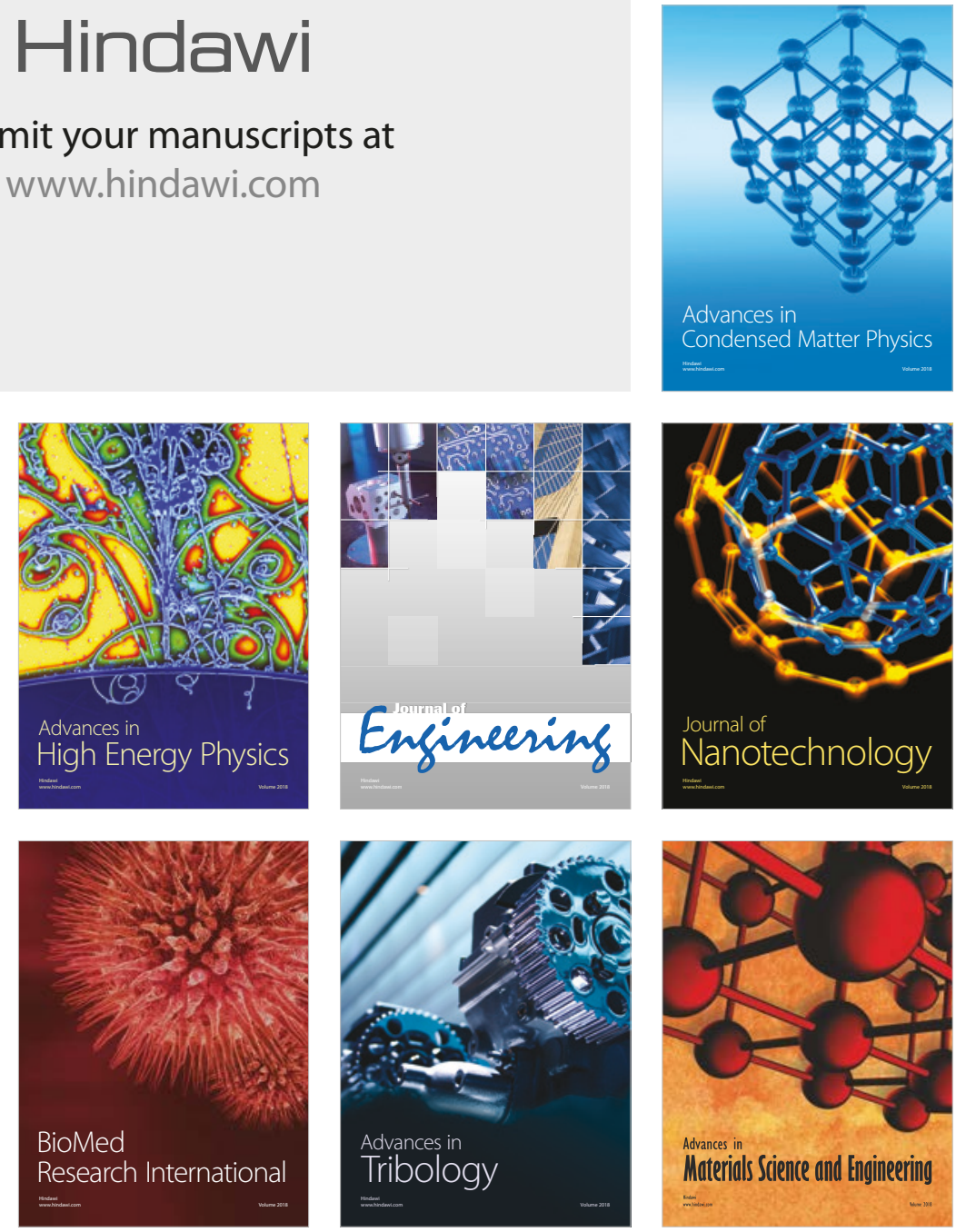